\title{
Towards explaining user satisfaction with contact tracing mobile applications in a time of pandemic: a text analytics approach
}

\author{
Morteza Namvar \\ The University of Queensland, Australia \\ m.namvar@business.uq.edu.au \\ Javad Pool \\ The University of Queensland, Australia \\ j.pool@uq.net.au
}

\author{
Saeed Akhlaghpour \\ The University of Queensland, Australia \\ s.akhlaghpour@business.uq.edu.au \\ Anisa Priscilia \\ The University of Queensland, Australia \\ a.priscilia@uq.net.au
}

\begin{abstract}
This research project investigates the critical phenomenon of the post-adoption use of Contact Tracing Mobile Applications (CTMAs) in a time of pandemic. A panel data set of customer reviews was collected from March 2020 to June 2021. Using sentiment analysis, topic modeling and dictionarybased analytics, 10,337 reviews were analyzed. The results show that after controlling for review sentiment and length, user satisfaction is associated with users' perception of utilitarian benefits of CTMA, their CTMAspecific privacy concerns, and installation and use issues. Our methodological approach (using various text analysis techniques for analyzing public feedback) and findings (influential factors on consumers' satisfaction with CTMA) can inform the design and deployment of the next generation of CTMAs for managing future pandemics.
\end{abstract}

\section{Introduction}

The nature and scale of the COVID-19 pandemic make digital tracing necessary for the mitigation of one of the most widespread and deadly pandemics the world has ever seen. By now, we know COVID-19 spreads quickly through people who are contagious but not sick, which makes it difficult to contain through conventional manual tracing alone [1]. Several researchers and technology vendors have proposed contact tracing mobile applications (CTMAs), such as TraceTogether in Singapore and COVIDSafe in Australia. These apps normally use location-based data and Bluetooth to track people and cryptography to protect users' privacy. Although there are still unanswered questions surrounding the individual and societal implications and unintended consequences of such tools, these CTMAs can provide healthcare workers and government officials with the data necessary to slow down the rate of infections and hospitalizations, but to also understand the spread of the virus - an essential insight for mitigating future viral outbreaks.
Given the recent high-profile privacy-loss events involving mobile apps and geolocation services [2], privacy advocates have elevated their messages, including warning citizens about the dangers, e.g., government surveillance, associated with apps designed to aid in fighting against COVID-19 [3]. These warnings, combined with the general desire for privacy shared by most mobile users, jeopardize the efficacy of the available CTMAs. Convincing users to participate and install these applications is a hurdle for public health officials and tech providers. Users must install one of these applications to become part of the network of tracing. However, many users may not adopt the applications because of privacy concerns - Singapore's TraceTogether app was reportedly adopted by only $10 \%-20 \%$ of the population [4].

Extensive research has been conducted on the adoption of information technologies (IT) and several influencing factors have been investigated in this decision process [5], [6]. Researchers have examined users' attitudes, beliefs, perceptions, effort and performance expectancies, and social influence related to adoption in various contexts, e.g., [7], [8]. However, given the novelty of the phenomenon and the rush in introducing remedial measures, little is known about the associations of consumers' reviews and their overall satisfaction with CMTAs. The role of privacy concerns, issues faced by the users, and the perceived benefits have not received enough empirical attention in the information systems (IS) research community. These factors are inevitably influential in people's decisions regarding continued use of technologies, especially in the context of public health [29, 30].

Therefore, the objective of this paper is to identify and validate the correlates of user satisfaction in the context of CTMAs, a novel aspect not previously considered in sentiment research. By investigating such differences, this study provides insights into the consistency between users' comments and their review ratings. 
Multiple opportunities exist for governments to improve the efficacy of their pandemic response measures through a better understanding of users' sentiments and emotions toward CMTAs. The findings of this study provide not only theoretical contributions but also provide public health authorities and governments with useful text analytics approaches to help them identify issues that matter most to users. This knowledge could consequently be used to develop more effective technologies and better public relations strategies.

\section{Positioning the study}

Lack of control and the high spread of COVID-19 threaten public health and restrict business operations and the global supply chain. In response to this pandemic, governments introduced social distancing as a public health intervention. However, this situation created an economic crisis. Consequently, business recovery depends on easing the restrictions on social distancing.

Effective use of digital technologies plays a vital role in managing this new crisis. Digital technologies have been recognized as an agile and efficient approach [9].
One effective digital intervention to control COVID-19 is using contact tracing technologies such as mobile apps. These technologies are effective and less resourceconsuming during the epidemic crisis than manual contact tracing [1]. Currently, there is great global attention to digital contact tracing technologies around the globe, from the US, East Asia to Australia [10]-[12]. A representative example of contact tracing technologies in Australia is the COVIDSafe app, one of the first apps of its kind, developed in April 2020 and recommenced by the Australian government and health officials to help stop the spread of the virus.

Since the COVID-19 pandemic, as complex and unthinkable phenomena, is new, there are limited studies on CMTAs with theoretical insight. Table 1 summarizes the studies that have investigated and reviewed contact tracing apps.

Our current research investigates CTMAs from social to technical, and epidemiological perspectives [13]-[16]. Thus, the contribution of our study to literature includes both social and technical perspectives, helping to understand this phenomenon from a multitude of perspectives. Figure 1 illustrates the boundary and contribution of this study to information systems literature and theory.

Table 1. Summaries of relevant research on CTMA

\begin{tabular}{|c|c|c|}
\hline Study & How CTMA was studied or conceptualized & Key findings/ insights \\
\hline Lin et al. [13] & $\begin{array}{l}\text { Focus on factors that influence willingness to adopt } \\
\text { the COVIDSafe app }\end{array}$ & $\begin{array}{l}\text { Trusting belief, relative advantage, and compatibility has } \\
\text { influenced intentions to use CTMA }\end{array}$ \\
\hline $\begin{array}{l}\text { Wymant et al. } \\
{[17]}\end{array}$ & $\begin{array}{l}\text { Focus on epidemiological impact of the NHS } \\
\text { COVID-19 app }\end{array}$ & $\begin{array}{l}\text { The NHS CTMA helped in the prevention of several hundred } \\
\text { thousand cases from arising for England and Wales. }\end{array}$ \\
\hline $\begin{array}{l}\text { De Carli et al. } \\
{[18]}\end{array}$ & $\begin{array}{l}\text { Focus on privacy-preserving and characteristics of } \\
\text { WeTrace: a contact tracing mobile app }\end{array}$ & $\begin{array}{l}\text { WeTrace application is a suitable system with regards to privacy } \\
\text { protection. WeTrace has features that potentially can meet the } \\
\text { EU GDPR requirements. }\end{array}$ \\
\hline $\begin{array}{l}\text { Yasaka et al. } \\
{[14]}\end{array}$ & $\begin{array}{l}\text { Focus on developing a contact tracing app and using } \\
\text { a computer simulation model }\end{array}$ & $\begin{array}{l}\text { Proposing a peer-to-peer contact tracing app that protects } \\
\text { personal data (e.g., location). }\end{array}$ \\
\hline Cho et al. [19] & $\begin{array}{l}\text { Focus on privacy implications of the tracking apps } \\
\text { such as Singapore's TraceTogether app }\end{array}$ & $\begin{array}{l}\text { Privacy is a central feature of contact tracing apps. There are } \\
\text { Several identified privacy-related issues, which highlight the } \\
\text { development of alternative solutions with stronger data } \\
\text { protection. }\end{array}$ \\
\hline Park et al. [15] & $\begin{array}{l}\text { Focus on response to COVID-19 in South Korea and } \\
\text { privacy concerns }\end{array}$ & $\begin{array}{l}\text { Using intervention measures such as digital-based contact } \\
\text { tracing helped South Korea to flatten the curve. However, } \\
\text { concerns are raised over data privacy involving contact tracing. }\end{array}$ \\
\hline Watts [20] & Focus on legal framework analysis & $\begin{array}{l}\text { A temporary legal framework does address privacy concerns. } \\
\text { However, there are a variety of legal risks that must be } \\
\text { addressed by the government. }\end{array}$ \\
\hline $\begin{array}{l}\text { Hassandoust et } \\
\text { al. [21] }\end{array}$ & $\begin{array}{l}\text { Focus on explaining CTMA adoption by developing } \\
\text { a situational privacy calculus model }\end{array}$ & $\begin{array}{l}\text { Individuals' intention to install a CTMA is influenced by their } \\
\text { risk beliefs, perceived individual and societal benefits, privacy } \\
\text { concerns, privacy protection initiatives (legal and technical } \\
\text { protection), and technology features (anonymity and use of less } \\
\text { sensitive data). }\end{array}$ \\
\hline $\begin{array}{l}\text { Lockey et al. } \\
{[22]}\end{array}$ & $\begin{array}{l}\text { Focus on identifying profiles of people who are (not) } \\
\text { likely to have downloaded a CTMA in Australia }\end{array}$ & $\begin{array}{l}\text { A combination of education and wealth play a key role in } \\
\text { CTMA adoption. Political ideology and trust in government are } \\
\text { other influential factors. }\end{array}$ \\
\hline
\end{tabular}


Figure 2. Research model

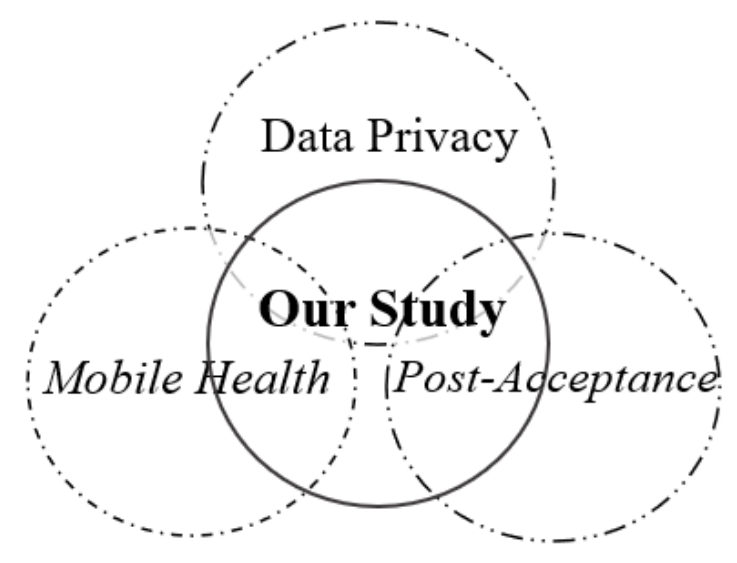

Figure 1. The study scope and contributions to the literature

\section{Hypotheses development}

This study investigates a digital artefact drawing upon the expectation-confirmation model of user satisfaction [23]. The expectation-confirmation model is an extension of the expectation confirmation theory, contextualized to the IS continuance and postacceptance [23]. We also sought to advance data privacy literature [24] through a data analytics approach. Further, our research is aligned with and contributes to mHealth literature since the use of CTMAs is a public health practice facilitated by mobile devices [25]. Figure 2 illustrates the conceptual model of our study (based on the expectation-confirmation model). In the following, we develop the main hypotheses of our study.

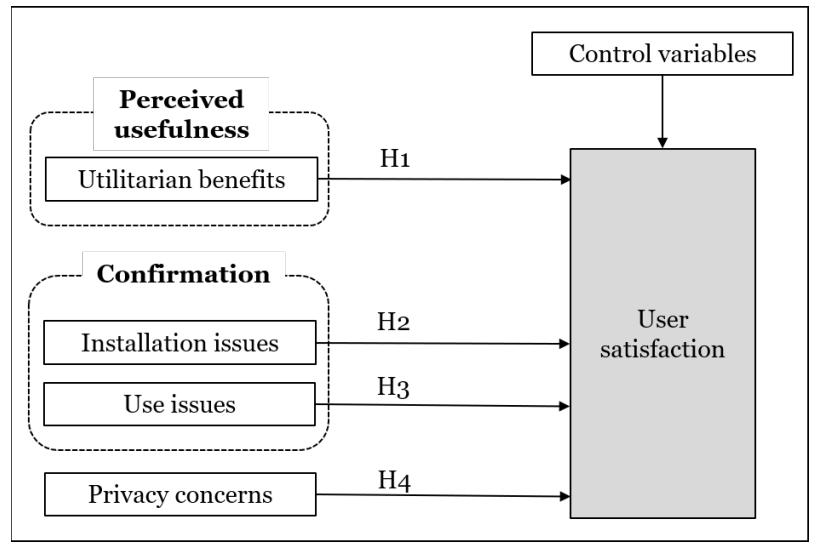

\subsection{Perceived usefulness and user satisfaction}

In an organizational context, perceived usefulness is defined as "the degree to which people believe using a particular system would enhance their job performance" [26]. More broadly, perceived usefulness refers to the expected benefit of IT perceived by users from the use of information technologies [23], [27]. In this study, the utilitarian benefits expressed by users captures perceived usefulness. The expectation-confirmation model posits that the perceived usefulness has an effect on users' satisfaction with the use of IT. The logic behind the association between perceived usefulness and satisfaction is grounded from the need- needsatisfaction perspective [28]. This perspective indicated that the fulfilment of users' needs is a key antecedent of satisfaction [29]. Deducted from the need-fulfilment perspective, instrumental concepts such as utilitarian benefit can be associated with users' satisfaction [30]. Prior research, aligned with the expectationconfirmation model, has demonstrated a consistent impact of perceived usefulness on user satisfaction [27], [31]-[33]. Hence, we propose the following hypothesis:

H1. Users' perceived usefulness (utilitarian benefits) is associated with their satisfaction with CTMAs use.

\subsection{Confirmation and user satisfaction}

Building upon the expectation-confirmation model, satisfaction is predicted by users' confirmation of expectations [23], [31]. Confirmation is defined as "users' perception of the congruence between the expectation of [IS] use and its actual performance" [23]. Once the users interact and use information systems, positive or negative expectations can be formed [28]. This expectation derives a level of satisfaction [31]. In this study on CTMAs, confirmation is measured by analyzing installation issues and use issues. Based on our inductive analysis of app reviews, as a public health digital tool, users expect CTMAs not to have installation and use issues. Once the users of expectations are (dis)confirmed based on the experience of the use of IT, an important consequence is users' (dis)satisfaction [23], [34]. The relationships between confirmation and user satisfaction have been supported by several studies [27], [35]-[37]. For instance, a study on the use of video-on-demand services revealed that confirmation was significant in explaining users' satisfaction [38]. Hence, we propose the following hypotheses: 
H2. Installation issues are associated with users' satisfaction with CTMAs use.

H3. Use issues are associated with users' satisfaction with CTMAs use.

\subsection{Privacy concerns and user satisfaction}

Adoption and widespread use of contact tracing technology require understanding people's attitudes and concerns towards the use of CTMAs. The low rate of adoption and use of CTMAs make this kind of intervention relatively ineffective [39]. Epidemic control can be achieved once sufficient people use CTMAs [1]. One fundamental question raised from the use of contact tracing apps is user privacy and data protection concerns [11], [15]. In this study, we adopt a broad definition of privacy concerns as 'individuals' perceptions of the consequences of sharing information through a CTMA." [29] This definition encompasses privacy concerns regarding the secondary use of data [40]. Privacy concerns can limit the adoption of CTMAs. The impact of privacy concerns is highlighted in the initial adoption decision and post-adoption use of digital technologies such as CTMAs [41]. Users have certain expectations about the privacy protection of a system as key criteria of system success [42]. Loss of control of personal data can reduce users' satisfaction. Past research indicated that privacy concerns about misuse or unauthorized access and surveillance could produce fear, anger, anxiety, negative cognition [11], [43]. The concerns related to data processing undermine user satisfaction [11], [44]. The effect of privacy concerns on user satisfaction is highlighted in different contexts such as social network community [11], human resource system, and mobile apps [42], [44]. This leads to proposing the following hypothesis:

H4. Users' Privacy concerns are associated with their satisfaction with CTMAs use.

\section{Research method}

Figure 3 shows the research process consisting of three main steps: data pre-processing, developing the main constructs and control variables and statistical analysis. In the first step, we collected 10,337 reviews of the COVIDSafe app in Australia between Apr 2020 to June 2021. The following data items were extracted for each review: star rating, review title, review date, and review text. In addition, information about the reviewer, including reviewer ID and app version, were also retrieved. For the purpose of our analysis, we operationalized user satisfaction as the star rating provided by the users. Review rating is the overall judgment of reviewers' experiences of the quality of a product or service [45]. Numerical reviewer ratings, in many instances, are available in a Likert scale format, ranging from 1 to 5 , reflecting the negative, neutral, or positive evaluation of the quality of a product or service [46]. In the current literature, a review rating is considered a valid proxy for identifying a user's overall satisfaction with products and services [47].

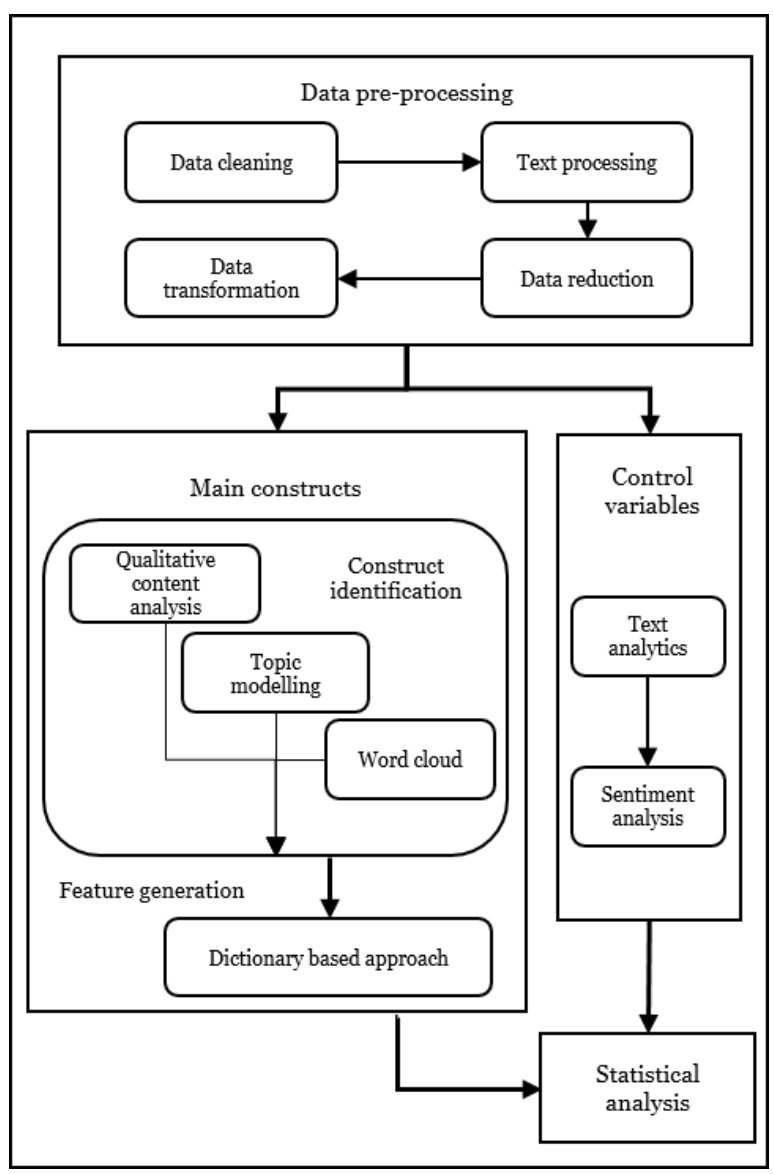

Figure 3. Research method followed

\subsection{Main constructs}

We used dictionary-based automated content analysis [48] to measure four main constructs of our research model, utilitarian benefits, privacy concerns, installation issues, and use issues. We generated four different dictionaries for content analysis [49]. In doing so, we first applied a qualitative content analysis. Two researchers analyzed a random sample of 370 reviews (roughly $4 \%$ of the text corpus) and coded the reviews using Nvivo. This step provides us with a pool of potential concepts and associated quotes. However, the 
relative importance of these concepts was not determined at this stage.

Second, we used text analysis and the WordCloud library in Python to visualize the most common words in reviews (see Figure 4). The most frequent words (and their frequency) included: phone (3070), number (2445), work (1982), battery (1449), Bluetooth (1342), install (1195), download (1183), try (1132), keep, 1121), time (1016), need (921), registration (871), mobile (845), easy (845), invalid (831), turn (783), help (768), issue (724), notification (710), update (707), location (616), uninstall (570), safe (529), government (519), drain (498), fix (494), pin (475), problem (450), connect (434), stop (419), open (414), accept (402), know (394), idea (386), contact (384).

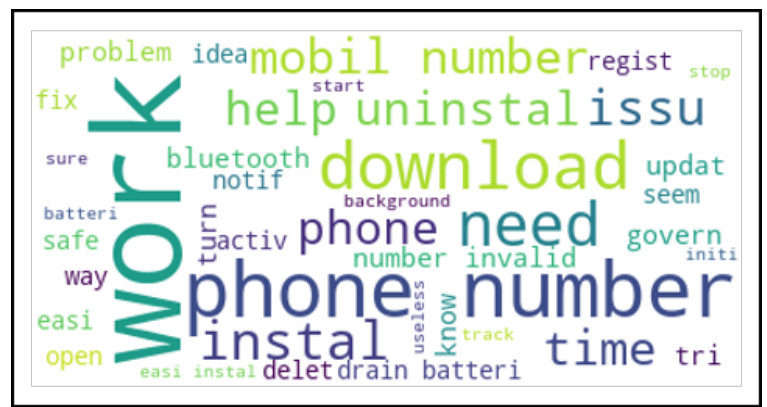

Figure 4. WordCloud of top 30 frequent words

Table 2. Main constructs and their final codes

\begin{tabular}{|c|c|c|}
\hline Construct & Frequent words & Representative quotes from qualitative analysis \\
\hline $\begin{array}{l}\text { Utilitarian } \\
\text { benefits }\end{array}$ & $\begin{array}{l}\text { contact, safe, } \\
\text { protection, } \\
\text { check, support, } \\
\text { trace, spread, } \\
\text { optimize, initiate }\end{array}$ & $\begin{array}{l}\text { "Great tool for gather information about the spread" } \\
\text { "I have downloaded this app for the sake of keeping myself very much in contact away from } \\
\text { people who might have tested positive to the virus but Mr Morrison I have fully downloaded } \\
\text { The covid safe app to keep myself away from other people who might have tested positive" } \\
\text { "All ok for the Safety of all Australians", "I see this is a way of keeping us all safe" }\end{array}$ \\
\hline $\begin{array}{l}\text { Installation } \\
\text { issues }\end{array}$ & $\begin{array}{l}\text { un/re-install, } \\
\text { invalid, fix, } \\
\text { code, pin, } \\
\text { problem, error, } \\
\text { fail, connect, } \\
\text { un/dis-able, } \\
\text { verify, delete }\end{array}$ & $\begin{array}{l}\text { "Disappointed that I can't install it on my wife's older phone" } \\
\text { "Also, tried to install on my wife's phone and no matter what we tried it kept saying invalid } \\
\text { phone number, did everything advised, still the same. Make it work properly and I'll put it } \\
\text { back on!!" } \\
\text { "On my stock Pixel } 2 \text { XL, I've attempted to register using networks and multiple installations } \\
\text { of the app and multiple phone number formats (as the app's help site advises), all multiple } \\
\text { times per day since launch, and, instead of sending me an activation code, I'm told to try } \\
\text { again later. Over and over again. After what must be well over one hundred attempts to } \\
\text { register, it's time to uninstall." }\end{array}$ \\
\hline Use issues & $\begin{array}{l}\text { battery, drain, } \\
\text { power, kill, } \\
\text { background, } \\
\text { Bluetooth, } \\
\text { Wi-Fi, screen, } \\
\text { power, sync, } \\
\text { constant, drop, } \\
\text { car, headphone, } \\
\text { charge, }\end{array}$ & $\begin{array}{l}\text { "I have had a lot of issues with my phone maintaining connection with other Bluetooth } \\
\text { devices. The worst instance was when it unpaired with my car which rendered my navigation } \\
\text { and voice control unusable until I rebooted and re-paired it." } \\
\text { "I'd like to be able to turn the app off while I'm driving alone in my car as the Bluetooth } \\
\text { pings off other people's app and it causes interruption to my music or GPS sounds. I can't } \\
\text { turn off the app through Bluetooth as this is how my phone connects to the car. Its irritating } \\
\text { in that way." } \\
\text { "it would drain a phones batteries faster to leave wifi and bluetooth active 24/7", } \\
\text { "Uses bugger all battery, doesn't interfere with other bluetooth devices"” } \\
\text { "it interrupts the use of my Bluetooth speaker and headphones so I've had o emporsrily } \\
\text { uninstall it" } \\
\text { "really wanted to do my bit, but I have given up using the app because it keeps signing me } \\
\text { out, even though I have the app open and Bluetooth on." } \\
\text { "Doesn't work on I phone unless open on front screen" }\end{array}$ \\
\hline $\begin{array}{l}\text { Privacy } \\
\text { concerns }\end{array}$ & $\begin{array}{l}\text { privacy, track, } \\
\text { violate, security, } \\
\text { permission, } \\
\text { requirement, } \\
\text { access, legal, } \\
\text { trust, hack, } \\
\text { store }\end{array}$ & $\begin{array}{l}\text { "I DO NOT like that the data is being stored by an American company. No matter that it is } \\
\text { Amazon Australia, it is still an American company" } \\
\text { "It's funny how my last rating dissappeared. Lets see who it hurts this time... I gave it } 1 \text { * } \\
\text { How are we supposed to trust our gov. to do the right thing with our data. Just look at what } \\
\text { they did with our phone and metadata. And is it correct to say under a State of Emergency; } \\
\text { privacy laws can be broken?" } \\
\text { "Today I lost my phone and because the COVIDSafe app was running, the person who found } \\
\text { my phone had complete access to EVERYTHING. Everything!!!! All my photos, notes, } \\
\text { contacts you name it. As much as I want to promote this app as it is important for tracing, } \\
\text { unfortunately, I will be deleting it. I was lucky that the person who found my phone was a } \\
\text { good person but when I think of all the damage they could have done given the details they } \\
\text { had access too, I cannot afford to take that chance again." } \\
\text { "Requires postcode for unknown reasons given it tracks you. Requires Bluetooth location } \\
\text { data because app is locating you." }\end{array}$ \\
\hline
\end{tabular}


Third, we applied topic modelling [50] using LDA (Latent Dirichlet Allocation) and extracted topics from the whole review texts. We then followed an abductive reasoning approach. Grounded in our empirical data and emergent findings, we searched for appropriate a priori theories (to be introduced at a later analytical stage) [51], [52]. LDA requires a determination of the number of topics underlying the corpus. Based on this abductive approach, we kept the top four topics, which provided an excellent fit to the three constructs of a relevant a priori theory (post-acceptance model of IS continuance derived from expectation-confirmation theory) [23]. We added Privacy Concerns to our model as the fourth construct that emerged from the data. The words collected from the above three steps were used as a guide for thematic analysis. We generated the list of words for each of the main four constructs of our proposed model. These codes include the frequent words associated with utilitarian benefits, privacy concerns, installation issues, and use issues. Table 2 presents the main four constructs, along with their codes used in our dictionary-based automated content analysis. Representative quotes illustrate how these constructs are manifested in this particular context.

In the final step of feature generation, we measured the value of the main four variables for each review based on the lists (dictionaries) generated in Table 4. For example, we focused on the number of terms in the category of "Privacy concerns" (exemplar terms are "privacy", "track" or "location"). We then divided the frequency of these terms by the overall length (number of words) for each review.

\subsection{Control variables}

To demonstrate the robustness of our observations and to compare the influence of review-related constructs with existing research, our proposed research model also takes into account two control variables, namely, review sentiment, and length. Although these variables are not the main focus of our research model their values could be related to user satisfaction. Sentiment is the quantification of the emotional direction of a review. As review ratings are the overall judgment of users about the quality of a product or service, based on the extant literature of online reviews [47], [53], [54], [55], [56] it is expected that reviews' sentiment will tend to match with reviewers' assigned ratings. Moreover, consistent with the current literature of online reviews [57], we expect that the length of reviews is associated with the user ratings of CMTAs. Using the Keras package in Python, we applied deep learning techniques to predict the sentiment score. We calculated review length by counting the number of words in each review.

\subsection{Statistical analysis}

We use negative binomial regression to test the hypotheses. Since the dependent variable (star rating) is a nonnegative count variable that ranges from 1 to 5 , it is inappropriate to use standard multiple regression. Considering that the mean of each level within our variables is larger than the variance of each level, our predictor variables are dispersed. Therefore, we apply the negative binomial regression model. This choice is in line with prior studies that investigate online reviews [58], as it can correct for over-dispersion [59].

\section{Results}

Table 3 presents the descriptive statistics and correlations for the variables. The highest correlation is between length and use issues at 0.41 . As our analysis did not indicate any high correlation, we did not remove any study variables. We mean-centered predictor variables before creating the interaction terms. To minimize the potential problem of multicollinearity, we also investigated the variance inflation factors (VIFs) for each model. We found that the VIFs ranged from 1 to 2.6, significantly lower than the generally accepted threshold of 10 , suggesting that multicollinearity does not impact our findings.

Table 3. Correlation analysis of the predictors

\begin{tabular}{|c|c|c|c|c|c|c|c|}
\hline & Attribute & 1 & 2 & 3 & 4 & 5 & 6 \\
\hline 1 & Sentiment & 1 & & & & & \\
\hline 2 & Length & 0.03 & 1 & & & & \\
\hline 3 & $\begin{array}{l}\text { Utilitarian } \\
\text { benefits }\end{array}$ & 0.37 & 0.37 & 1 & & & \\
\hline 4 & $\begin{array}{l}\text { Privacy } \\
\text { concerns }\end{array}$ & 0.36 & 0.36 & 0.16 & 1 & & \\
\hline 5 & $\begin{array}{l}\text { Instillatio } \\
\mathrm{n} \text { issues }\end{array}$ & -0.15 & 0.32 & 0.05 & 0.00 & 1 & \\
\hline 6 & Use issues & -0.12 & 0.41 & 0.28 & 0.06 & 0.13 & 1 \\
\hline
\end{tabular}

Table 4 presents the estimation results of the negative binomial models. We developed two models. Model 0 is the base model containing control variables. Results indicate that lengthy reviewers and reviews with positive sentiments are expected to provide higher star ratings (user satisfaction). These results are consistent with prior studies [60]. Model 1 relates to the effect of main constructs on user satisfaction (star rating) with other variables as controls. 
Table 4. Negative binomial regression explaining review helpfulness $(n=10,337)$

\begin{tabular}{|lll|}
\hline & $\begin{array}{l}\text { Model 0 } \\
\text { Base model }\end{array}$ & $\begin{array}{l}\text { Model 1 } \\
\text { Main variables }\end{array}$ \\
\hline Sentiment & $1.1174^{* * *}(0.018)$ & $1.0594 * * *(0.019)$ \\
Length & $0.0190 * * *(0.000)$ & $0.0169 * * *(0.000)$ \\
\hline Utilitarian benefits & & $0.0834^{* * *}(0.006)$ \\
Installation issues & & $-0.0202 *(0.009)$ \\
Use issues & & $0.0702 * * *(0.010)$ \\
Privacy concerns & & $-0.0474 * *(0.013)$ \\
\hline Pearson chi2 & $4.90 \mathrm{e}+04$ & $4.82 \mathrm{e}+04$ \\
\hline Note: Robust Standard errors reported in parentheses for \\
coefficients, degrees of freedom for test statistics. \\
$* * *$ p $<0.001, * * \mathrm{p}<0.01$, and $*<0.05$ \\
\hline
\end{tabular}

Hypothesis 1 postulates that utilitarian benefits will be positively related to user satisfaction. The results in model 1 reveal that the coefficient for review order is positively significant (coefficient $=0.0834, p<0.000$ ) . Hypothesis 2 posited that the installation issues would be associated with user satisfaction. The results in model 1 reveal that the coefficient for installation issues is negatively significant (coefficient $=-0.0202, p$ $<0.05)$.

Hypothesis 3 assumes that use issues will be associate with user satisfaction. The results in model 1 indicate a positively significant coefficient (coefficient $=0.0702, \mathrm{p}<0.000$ ) for the interaction between use issues and user satisfaction. Hypothesis 4 proposes that privacy concerns will be associated with user satisfaction. The results in model 1 suggest that the coefficient for the interaction between privacy concern and use satisfaction is negative (coefficient $=-0.0474, p$ $<0.01)$.

To further test the robustness of our empirical results, we conducted additional analyses with alternative model specifications. We validated the robustness of our findings by using an alternative regression technique. We employed a zero-inflated negative binomial regression model (ZINB). Table 5 shows the new estimates. The results of the ZINB analysis are indeed similar to our results from the negative binomial regression analyses reported in Table 4.

Table 5. Robustness test $(n=10,337)$

\begin{tabular}{|l|c|}
\hline Length & $0.0169 * * *(0.000)$ \\
\hline Sentiment & $1.0595 * * *(0.019)$ \\
\hline Utilitarian benefits & $0.095 * * *(0.000)$ \\
\hline Installation issues & $-0.0203 *(0.009)$ \\
\hline Use issues & $0.0834 * *(0.006)$ \\
\hline Privacy concerns & $-0.0472 * * *(0.013)$ \\
\hline
\end{tabular}

As an alternative method for the robustness test, we computed the classic evaluation metric, accuracy. The results of our model building using Neural Networks (multi-layer perceptron) and cross-validation $(\mathrm{K}=10)$ indicate that the proposed model classifies user satisfaction with an average accuracy of $71.5 \%$. Considering that the unstructured data is collected solely from user reviews, the accuracy is acceptable. The model can be used when only user reviews are available, and the objective is to estimate user satisfaction.

\section{Conclusion and future work}

Online review platforms provide open, convenient communication channels for sharing and gathering consumer reviews. For governments and public health authorities, these online reviews represent unique and valuable information sources to understand the public perceptions about their digital services.

There have been earlier attempts to use sentiment analysis for understanding public reaction to CTMAs [61]. However, as admitted in those studies, sentiment analysis "will not identify the area of interest, identify the users' specific issues or, indeed, determine the prevalence of those issues across the datasets." Our study demonstrates an approach for going beyond automated sentiment analysis. We applied a mixedmethod analysis (a sequence of qualitative content analysis, LDA, and dictionary-based automated content analysis) in combination with established Information System theories for providing a rich and evidence-based understanding of user's attitudes and concerns towards CTMAs. We highlighted the statistically significant relationships among these attitudes and concerns (as expressed in textual comments) and the users' overall satisfaction with a CTMA. Both our methodological approach (in unearthing user attitudes, issues, and concerns) and findings can inform the design and deployment of the next generation of CTMAs for managing future pandemics.

This study, nevertheless, has certain limitations that can be explored in future research. The data for this study are reviews of a particular CTMA in Australia. It consists of the reviews from users who were willing to embrace technology because of underlying needs. Understanding the deterministic factors in the adoption of this technology for more generic users requires a different study with possibly a different research method and data collection. To generalize the results, future research can apply similar approaches to investigate other CTMAs with different architectures (e.g., centralized vs. decentralized, collecting Bluetooth vs. GPS data) in different geographies. Also, this study only includes the review sentiment and length in the regression model as covariates. Future studies can incorporate other covariates, including review time (visà-vis number and severity of outbreaks) and additional CTMA characteristics (if multiple CTMAs are 
concerned) into the model to obtain further insights for more effective and successful CTMA designs. Finally, our conceptual model was based on expectationconfirmation theory and studied the impacts of four main constructs on user satisfaction. Future research can use other theories, e.g., institutional theory, to study other factors, e.g., regulative, and normative pressures, on CTMA adoption and use.

\section{Acknowledgements}

The authors thank the minitrack co-chairs and anonymous reviewers for their feedback and guidance. We also thank Salma Sharifi Khajedehi for her helpful research assistance in literature review and manuscript revision.

\section{References}

[1] L. Ferretti et al., "Quantifying SARS-CoV-2 transmission suggests epidemic control with digital contact tracing," Science, vol. 368, no. 6491, 2020.

[2] J. Valentino-DeVries, N. Singer, M. H. Keller, and A. Krolik, "Your apps know where you were last night, and they're not keeping it secret," New York Times, vol. 8, no. 1, 2019.

[3] F. Rowe, O. Ngwenyama, and J.-L. Richet, "Contacttracing apps and alienation in the age of COVID-19," European Journal of Information Systems, vol. 29, no. 5, pp. 545-562, 2020.

[4] "Coronavirus: EU and Australian tracing apps 'ready in weeks," BBC., 2020. [Online]. Available: https://www.bbc.com/news/technology-52325352

[5] A. Burton-Jones, M.-K. Stein, and A. Mishra, "MISQ Research Curation on IS Use Research Curation Team," MIS Quarterly Research Curations, vol. 1, no. 1, pp. 1-24, 2017.

[6] S. Akhlaghpour and L. Lapointe, "From placebo to panacea: studying the diffusion of IT management techniques with ambiguous efficiencies: the case of capability maturity model," Journal of the Association for Information Systems, vol. 19, no. 6, p. 4, 2018.

[7] I. Im, S. Hong, and M. S. Kang, "An international comparison of technology adoption: Testing the UTAUT model," Information \& management, vol. 48, no. 1, pp. 1-8, 2011.

[8] T. Zhou, Y. Lu, and B. Wang, "Integrating TTF and UTAUT to explain mobile banking user adoption," Computers in human behavior, vol. 26, no. 4, pp. 760-767, 2010.

[9] S. Mahmood, K. Hasan, M. C. Carras, and A. Labrique, "Global preparedness against COVID-19: We must leverage the power of digital health," JMIR Public Health and Surveillance, vol. 6, no. 2, p. e18980, 2020.
[10] Z. Doffman, "orget Apple And Google-Here's The Real Challenge For COVID-19 Contact-Tracing," Forbes, 2020.

[11] Y. Huang, M. Sun, and Y. Sui, "How digital contact tracing slowed Covid-19 in East Asia," Harvard Business Review, vol. 15, no. 04, 2020.

[12] J. Taylor, "Covidsafe app: how Australia's coronavirus contact tracing app works, what it does, downloads and problems," The Guardian, 2020.

[13] J. Lin, L. Carter, and D. Liu, "Privacy concerns and digital government: exploring citizen willingness to adopt the COVIDSafe app," European Journal of Information Systems, pp. 1-14, 2021.

[14] T. M. Yasaka, B. M. Lehrich, and R. Sahyouni, "Peer-topeer contact tracing: development of a privacy-preserving smartphone app," JMIR mHealth and uHealth, vol. 8, no. 4, p. e18936, 2020.

[15] S. Park, G. J. Choi, and H. Ko, "Information technologybased tracing strategy in response to COVID-19 in South Korea-privacy controversies," Jama, vol. 323, no. 21, pp. 2129-2130, 2020.

[16] J. Abeler, M. Bäcker, U. Buermeyer, and H. Zillessen, "COVID-19 contact tracing and data protection can go together," JMIR mHealth and uHealth, vol. 8, no. 4, p. e19359, 2020.

[17] C. Wymant et al., "The epidemiological impact of the NHS COVID-19 App,” Nature, pp. 1-8, 2021.

[18] A. De Carli et al., "WeTrace-a privacy-preserving mobile COVID-19 tracing approach and application," 2020, [Online]. Available: arXiv preprint arXiv:2004.08812

[19] H. Cho, D. Ippolito, and Y. W. Yu, "Contact tracing mobile apps for COVID-19: Privacy considerations and related trade-offs," 2020, [Online]. Available: https://arxiv.org/abs/2003.11511

[20] D. Watts, "Covidsafe, Australia's digital contact tracing app: the legal issues," Australia's Digital Contact Tracing App: The Legal Issues (May 2, 2020), 2020.

[21] F. Hassandoust, S. Akhlaghpour, and A. C. Johnston, "Individuals' privacy concerns and adoption of contact tracing mobile applications in a pandemic: A situational privacy calculus perspective," Journal of the American Medical Informatics Association, vol. 28, no. 3, pp. 463-471, Mar. 2021.

[22] S. Lockey, M. R. Edwards, M. J. Hornsey, N. Gillespie, S. Akhlaghpour, and S. Colville, "Profiling adopters (and nonadopters) of a contact tracing mobile application: Insights from Australia," International Journal of Medical Informatics, vol. 149, p. 104414, May 2021.

[23] A. Bhattacherjee, "Understanding information systems continuance: An expectation-confirmation model," MIS quarterly, pp. 351-370, 2001. 
[24] H. J. Smith, T. Dinev, and H. Xu, "Information privacy research: an interdisciplinary review," MIS quarterly, pp. 989 $1015,2011$.

[25] B. Martínez-Pérez, I. De La Torre-Díez, and M. LópezCoronado, "Privacy and security in mobile health apps: a review and recommendations," Journal of medical systems, vol. 39, no. 1, pp. 1-8, 2015.

[26] K. H. Lim and I. Benbasat, "The effect of multimedia on perceived equivocality and perceived usefulness of information systems," MIS quarterly, pp. 449-471, 2000.

[27] A. P. Oghuma, C. F. Libaque-Saenz, S. F. Wong, and Y. Chang, "An expectation-confirmation model of continuance intention to use mobile instant messaging," Telematics and Informatics, vol. 33, no. 1, pp. 34-47, 2016.

[28] A. Bhattacherjee and C.-P. Lin, "A unified model of IT continuance: three complementary perspectives and crossover effects," European Journal of Information Systems, vol. 24, no. 4, pp. 364-373, 2015.

[29] N. Au, E. W. Ngai, and T. E. Cheng, "Extending the understanding of end user information systems satisfaction formation: An equitable needs fulfillment model approach," MIS quarterly, vol. 32, no. 1, pp. 43-66, 2008.

[30] Z. Zhou, X.-L. Jin, and Y. Fang, "Moderating role of gender in the relationships between perceived benefits and satisfaction in social virtual world continuance," Decision Support Systems, vol. 65, pp. 69-79, 2014.

[31] J.-J. Hew, V.-H. Lee, K.-B. Ooi, and B. Lin, "Mobile social commerce: The booster for brand loyalty?," Computers in Human Behavior, vol. 59, pp. 142-154, 2016.

[32] W. Chiu, H. Cho, and C. G. Chi, "Consumers' continuance intention to use fitness and health apps: an integration of the expectation-confirmation model and investment model," Information Technology \& People, 2020. [33] L. Wu, M.-L. Chiu, and K.-W. Chen, "Defining the determinants of online impulse buying through a shopping process of integrating perceived risk, expectationconfirmation model, and flow theory issues," International Journal of Information Management, vol. 52, p. 102099, 2020. [34] K. Nam, J. Baker, N. Ahmad, and J. Goo, "Determinants of writing positive and negative electronic word-of-mouth: Empirical evidence for two types of expectation confirmation," Decision Support Systems, vol. 129, p. 113168, Feb. 2020.

[35] C. Tam, D. Santos, and T. Oliveira, "Exploring the influential factors of continuance intention to use mobile Apps: Extending the expectation confirmation model," Information Systems Frontiers, vol. 22, no. 1, pp. 243-257, Feb. 2020.

[36] C.-L. Hsu and J. C.-C. Lin, "What drives purchase intention for paid mobile apps? - An expectation confirmation model with perceived value," Electronic Commerce Research and Applications, vol. 14, no. 1, pp. 46-57, Jan. 2015.
[37] T.-C. Lin, S. Wu, J. S.-C. Hsu, and Y.-C. Chou, "The integration of value-based adoption and expectationconfirmation models: An example of IPTV continuance intention," Decision Support Systems, vol. 54, no. 1, pp. 6375, Dec. 2012.

[38] R. Pereira and C. Tam, "Impact of enjoyment on the usage continuance intention of video-on-demand services," Information \& Management, vol. 58, no. 7, p. 103501, 2021.

[39] S. Shaed, "UK's coronavirus contact-tracing app to be ready for 'wider deployment' in 2-3 weeks," CNBC, 2020. [Online].

Available: https://www.cnbc.com/2020/04/29/coronavirus-uk-contacttracing-app-ready-in-2-3-weeks.html

[40] N. Thompson, T. McGill, A. Bunn, and R. Alexander, "Cultural factors and the role of privacy concerns in acceptance of government surveillance," Journal of the Association for Information Science and Technology, vol. 71, no. 9, pp. 1129-1142, 2020.

[41] G. Fox, T. Clohessy, L. van der Werff, P. Rosati, and T. Lynn, "Exploring the competing influences of privacy concerns and positive beliefs on citizen acceptance of contact tracing mobile applications," Computers in Human Behavior, vol. 121, p. 106806, Aug. 2021.

[42] A. Kobsa, H. Cho, and B. P. Knijnenburg, "The effect of personalization provider characteristics on privacy attitudes and behaviors: An Elaboration Likelihood Model approach," Journal of the Association for Information Science and Technology, vol. 67, no. 11, pp. 2587-2606, 2016.

[43] A. B. Yost, T. S. Behrend, G. Howardson, J. Badger Darrow, and J. M. Jensen, "Reactance to Electronic Surveillance: a Test of Antecedents and Outcomes," Journal of Business and Psychology, vol. 34, no. 1, pp. 71-86, Feb. 2019.

[44] L. Gao, K. A. Waechter, and X. Bai, "Understanding consumers' continuance intention towards mobile purchase: A theoretical framework and empirical study - A case of China," Computers in Human Behavior, vol. 53, pp. 249-262, Dec. 2015.

[45] S. Moon, P. K. Bergey, and D. Iacobucci, "Dynamic Effects among Movie Ratings, Movie Revenues, and Viewer Satisfaction:," Journal of Marketing, vol. 74, pp. 108-121, 2010.

[46] S. M. Mudambi and D. Schuff, "Research note: What makes a helpful online review? A study of customer reviews on Amazon.com," MIS quarterly, vol. 34, no. 1, pp. 185-200, 2010.

[47] M. Salehan and D. J. Kim, "Predicting the performance of online consumer reviews: A sentiment mining approach to big data analytics," Decision Support Systems, vol. 81, pp. 3040, 2016.

[48] S. D. Rosenberg, P. P. Schnurr, and T. E. Oxman, "Content analysis: A comparison of manual and computerized 
systems," Journal of personality assessment, vol. 54, no. 1-2, pp. 298-310, 1990.

[49] P. J. Stone, R. F. Bales, J. Z. Namenwirth, and D. M. Ogilvie, "The general inquirer: A computer system for content analysis and retrieval based on the sentence as a unit of information," Behavioral Science, vol. 7, no. 4, p. 484, 1962.

[50] S. Yang, C. Zhou, and Y. Chen, "Do topic consistency and linguistic style similarity affect online review helpfulness? An elaboration likelihood model perspective," Information Processing \& Management, vol. 58, no. 3, p. 102521, May 2021.

[51] D. A. Gioia, K. G. Corley, and A. L. Hamilton, "Seeking Qualitative Rigor in Inductive Research: Notes on the Gioia Methodology," Organizational Research Methods, vol. 16, no. 1, pp. 15-31, Jan. 2013.

[52] C. Urquhart and W. Fernández, "Using Grounded Theory Method in Information Systems: The Researcher as Blank Slate and Other Myths," in Enacting Research Methods in Information Systems: Volume 1, L. P. Willcocks, C. Sauer, and M. C. Lacity, Eds. Cham: Springer International Publishing, 2016, pp. 129-156.

[53] A. Y. K. Chua and S. Banerjee, "Helpfulness of usergenerated reviews as a function of review sentiment, product type and information quality," Computers in Human Behavior, vol. 54, pp. 547-554, 2016.

[54] A. K. Jha and S. Shah, "Social Influence on Future Review Sentiments: An Appraisal-Theoretic View," Journal of Management Information Systems, vol. 36, no. 2, pp. 610 638, 2019.

[55] M. Namvar, "A Novel Approach to Predict the Helpfulness of Online Reviews," presented at the Hawaii International Conference on System Sciences, Hawaii, Jan. 2020.

[56] M. Namvar, J. Boyce, J. Sarna, Y. Zheng, A. Chua Yeow Kuan, and S. Ameli, Moderating Effects of Time-Related Factors in Predicting the Helpfulness of Online Reviews: a Deep Learning Approach. 2021.

[57] B. Lutz and N. PrÃ, "The Longer the Better? The Interplay Between Review Length and Line of Argumentation in Online Consumer Reviews," presented at the international conference on information systems, Munich, Dec. 2019.
[58] S. Zhou and B. Guo, "The order effect on online review helpfulness: A social influence perspective," Decision Support Systems, vol. 93, pp. 77-87, 2017.

[59] Z. (John) Lin, M. W. Peng, H. Yang, and S. L. Sun, "How do networks and learning drive M\&As? An institutional comparison between China and the United States," Strategic Management Journal, vol. 30, no. 10, pp. 1113-1132, 2009.

[60] M. Ghasemaghaei, S. P. Eslami, K. Deal, and K. Hassanein, "Reviews' length and sentiment as correlates of online reviews' ratings," Internet Research, vol. 28, no. 3, pp. 544-563, 2018.

[61] K. Rekanar et al., "Sentiment analysis of user feedback on the HSE's Covid-19 contact tracing app," Irish Journal of Medical Science (1971 -), Feb. 2021. 